\title{
CARDIAC INVOLVEMENT IN ERYTHEMA NODOSUM ASSOCIATED WITH PULMONARY TUBERCULOSIS
}

BY

\section{J. W. B. FORSHAW}

From the Royal Southern Hospital, Liverpool

Erythema nodosum is now generally considered to be a response of the body which may be provoked by bacteria or chemical agents. The condition is often a manifestation of sarcoidosis (James et al., 1956) although a number of cases are associated with pulmonary tuberculosis (Middlemiss, 1949; Wynn-Williams and Edwards, 1954). Hæmolytic streptococci and sulphonamide drugs are the responsible agents in a minority of cases.

Evidence of cardiac involvement in erythema nodosum has rarely been reported. Neidhart and Rumrich (1950) have described four cases of erythema nodosum associated with pulmonary tuberculosis, in which there was clinical and electrocardiographic evidence of myocarditis. However, in the larger series of cases of erythema nodosum which have been reported recently (Middlemiss, 1949; Wynn-Williams and Edwards, 1954; James et al., 1956) there has been no mention of cardiac involvement, but electrocardiograms have not usually been done.

The present report is of a case in which there was electrocardiographic and clinical evidence of myocardial damage during an attack of erythema nodosum. Subsequently the cardiogram reverted to normal, and radiographic evidence of pulmonary tuberculosis developed.

\section{Case Report}

A boy, aged 17, was admitted to hospital in January 1957. One week previously he had developed painful red lumps on both legs, an intermittent sharp pain in the left side of his chest, and general malaise with shivering, sweating, and anorexia. The only previous illness was an attack of tonsillitis which he had had one year previously. Two years previously his brother had pulmonary tuberculosis; at this time the patient's chest radiograph was normal and his Mantoux test was positive at $1: 100$ dilution.

On examination, he was a well-nourished youth with a healthy general appearance. His temperature was raised to $102^{\circ} \mathrm{F}$., and there were numerous tender red nodules on both legs. There were systolic murmurs of moderate intensity at the apex and the pulmonary areas of the heart but there were no signs of cardiac enlargement. The joints appeared normal and the fauces were not inflamed.

Investigations. Hæmoglobin 83 per cent $(12 \cdot 3 \mathrm{~g}$.); white blood cells 8100 per cu. $\mathrm{mm}$. (normal differential count); E.S.R. (Wintrobe) $49 \mathrm{~mm}$. in one hour. Urine normal. Throat swab culture, no growth of hæmolytic streptococci. Chest radiograph, some enlargement of the hilar glands but lung fields normal. Electrocardiograms showed deep inversion of the T waves in leads II, III, and V6, and raised S-T segments in leads V2 and V4 (Fig. 1).

Treatment and Progress. Calcium aspirin 20 grains q.i.d. was given for six days, and then 10 grains t.i.d. foi 17 days. The pyrexia settled on the fourth day of treatment, and the E.S.R. fell to $7 \mathrm{~mm}$. in one hour within three weeks. The erythema nodosum cleared up over a period of ten days. Serial electrocardiograms taken over a period of ten weeks showed that the T waves in leads II and V6 were upright six days after the start of calcium aspirin therapy, and that the T wave in lead III gradually became less inverted. The S-T segments in leads V2 and V4 remained persistently raised.

At the time of his discharge from hospital, seven weeks after the onset of the illness, the patient was free from symptoms but the cardiac murmurs were still present. He remained free from symptoms when 


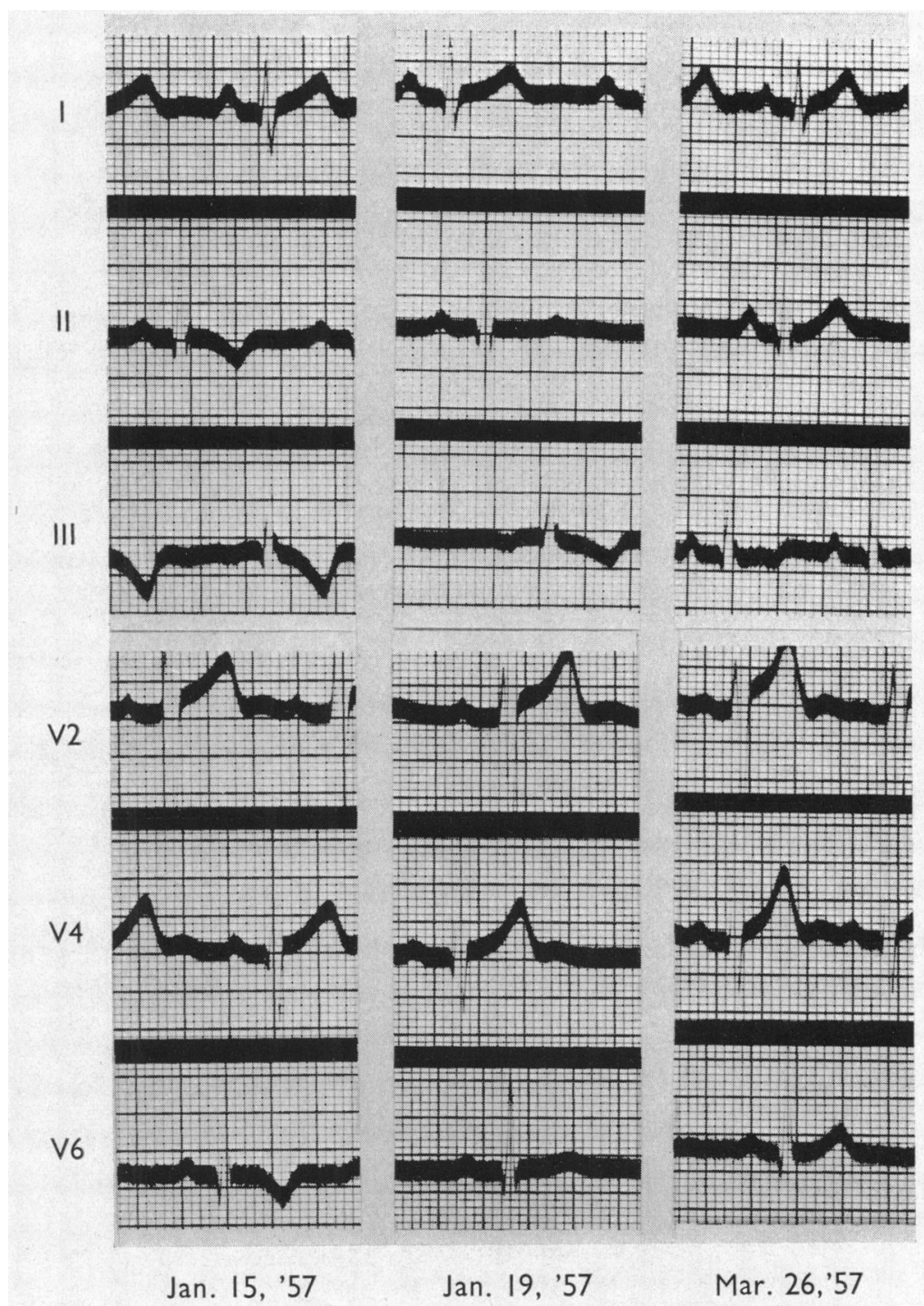

Fig. 1.-Electrocardiograms, showing inversion of $\mathrm{T}$ waves in leads II, III, and V6 during attack of erythema nodosum and subsequent reversion to normal.

he attended the out-patient clinic one month later, but a further radiograph of the chest showed the development of an opacity in the right lung in the region of the second intercostal space.

Two months later (June, 1957) a further radiograph showed no change in the appearance of the right lung and hilum. The E.S.R. was raised to $27 \mathrm{~mm}$. in one hour, and the Mantoux test was strongly positive $(1: 1000$ dilution). He was unable to produce any sputum, but examination of gastric washings for tubercle bacilli was negative. The cardiac systolic murmurs had now disappeared.

In view of the appearance of the chest radiographs and the strongly positive Mantoux test, a presumptive diagnosis of pulmonary tuberculosis was made and treatment was started with streptomycin $1 \mathrm{~g}$. daily and isoniazid $100 \mathrm{mg}$. three times daily. This treatment has been continued, and a radiograph in October showed that there was some resolution of the lesion in the right upper lobe. 


\section{Discussion}

The myocardium may be involved in allergic conditions such as serum sickness (Contro and Mond, 1956; Roussak, 1954), drug reactions (Pfister and Plice, 1950; Lilienfield et al., 1950), and anaphylactoid purpura (MacGregor and Vallance-Owen, 1957), and it seems probable that the same pathological process affects the myocardium in erythema nodosum. The myocardium may rarely be directly affected by tuberculosis (Schnitzer, 1947) or sarcoidosis (Scotti and McKeown, 1948 ), but in the present case the electrocardiogram was only altered temporarily and it is more likely, therefore, that the myocardium was damaged by an allergic reaction than by infiltration with tuberculous granulation tissue.

In this case and in the four others reported with evidence of cardiac involvement (Neidhart and Rumrich, 1950), the erythema nodosum was associated with pulmonary tuberculosis. In view of the frequent production of heart disease by hæmolytic streptococci in rheumatic fever it is surprising that evidence of heart disease has not been noted in cases of erythema nodosum associated with hæmolytic streptococcal infection. Perry (1944) considered that erythema nodosum associated with hæmolytic streptococcal infection should not be regarded as a manifestation of rheumatic fever, and that when erythema nodosum was accompanied by signs of rheumatic fever they were two separate sequelæ to the same streptococcal infection. It is probable, however, that this distinction between erythema nodosum and rheumatic fever may not usually be made, and that cases of streptococcal erythema nodosum with evidence of heart disease tend to be diagnosed as rheumatic fever and are excluded from the reported series of cases of erythema nodosum.

\section{Summary}

Signs of myocardial damage appeared in a youth during an attack of erythema nodosum. There was no evidence of hæmolytic streptococcal infection, and two months after the onset of the disease he developed radiographic evidence of pulmonary tuberculosis.

It is suggested that the cardiac manifestations were due to an allergic reaction rather than to tuberculous infiltration of the myocardium.

A review of previously reported cases suggests that involvement of the heart in erythema nodosum rarely occurs.

I wish to thank Dr. G. M. S. Ryan for permission to publish this case.

\section{References}

Contro, S., and Mond, E. (1956). Amer. Heart J., 52, 510.

James, D. G., Thomson, H. D., and Willcox, H. (1956). Lancet, 2, 218.

Lilienfield, A., Hockstein, E., and Weiss, W. (1950). Circulation, 1, 1060.

MacGregor, G. A., and Vallance-Owen, J. (1957). Lancet, 2, 572.

Middlemiss, J. H. (1949). Brit. J. Radiol., 22, 375.

Neidhart, K., and Rumrich, R. (1950). Disch. med. Wschr., 75, 667.

Perry, C. B. (1944). Brit. med. J., 2, 843.

Pfister, C. W., and Plice, S. G. (1950). Amer. Heart J., 40, 945.

Roussak, N. J. (1954). Brit. Heart J., 16, 218.

Schnitzer, R. (1947). Brit. Heart J., 9, 213.

Scotti, T. M., and McKeown, C. E. (1948). Arch. Path., 46, 289.

Wynn-Williams, N., and Edwards, G. F. (1954). Lancet, 1, 278. 